\title{
Autologous Adipose Stem Cell Therapy for Autonomic Nervous System Dysfunction in Two Young Patients
}

\author{
Mohammed T. Numan, Ankur Kamdar, Jane Young, and lan. J. Butler ${ }^{1}$
}

\begin{abstract}
Postural orthostatic tachycardia syndrome and neurocardiogenic syncope are clinical manifestations of autonomic nervous system dysfunction (dysautonomia) that can lead to impaired daily functions. We report two young patients presenting with dysautonomia and autoimmune disease who both received autologous adipose stem cells (ASCs) infusions. This report is the first description of ASCs therapy for patients with combined dysautonomia and autoimmune disease. Case 1: A 21-year-old female presented at 12 years of age with escalating severe dysautonomia with weight loss and gastrointestinal symptoms. She had elevated autoantibodies and cytokines and received multiple immune modulation therapies. Her dysautonomia was treated by volume expanders, vasoconstrictors, and beta blockers with mild improvement. She received ASCs about 2 years before this report with dramatic improvement in her dysautonomia and autoimmune symptoms with a $10 \mathrm{~kg}$ weight gain. Case 2: A 7-year-old boy presented at 2 years of age with polyarthritis. At 5 years of age, he manifested orthostatic intolerance. He received immune modulatory therapies with mild improvement. He received ASCs and showed marked improvement of his dysautonomia and immune symptoms. Dysautonomia symptoms of these two patients improved significantly after modulation of autoimmune components by ASC therapy. Favorable clinical responses of these two cases warrant further case-control studies.
\end{abstract}

Keywords: CNS, concise report, immunogenicity

\section{Introduction}

$\mathrm{O}$ RTHOSTATIC INTOLERANCE (OI), postural orthostatic tachycardia syndrome, and neurocardiogenic syncope in young patients are clinical manifestations caused by autonomic nervous system dysfunction (dysautonomia) [1]. Children with clinical manifestations of dysautonomia often have disturbances in life style [2]. Medical management of these patients requires multiple drugs and physical rehabilitation with mixed clinical responses. Adipose stem cells (ASCs) have anti-inflammatory effects, reducing inflammatory cytokines [3]. We report a unique clinical experience in two young patients with severe symptoms caused by autonomic dysfunction and autoimmune disease who underwent autologous ASC therapy.

\section{Methods}

\section{Study oversite}

This retrospective study of a small patient cohort was approved by our Institutional Review Board of The University of Texas Health Science Center, Houston, Texas.
Mesenchymal stem cell (MSC) preparation, a single tumescent liposuction procedure, obtained $20 \mathrm{~mL}$ of autologous abdominal subcutaneous fat tissue. Adipose tissue was digested with collagenase I at $37^{\circ} \mathrm{C}$ and centrifuged to isolated stromal vascular fractions. The collected pellet was resuspended in Dulbecco's modified Eagle's medium (Life Technologies) containing 10\% fetal bovine serum, followed by filtering through a $100 \mu \mathrm{m}$ cell strainer. The pellet was resuspended in specific selection medium and cultured overnight in a $37^{\circ} \mathrm{C} / 5 \% \mathrm{CO}_{2}$ incubator for the MSC to attach to the flask. After $24 \mathrm{~h}$, nonadherent cells were washed away with phosphate-buffered saline, and adherent cells were cultured in specific MSC growth medium. For each passage, cells were cultured and expanded until they reached $\sim 90 \%$ confluence [up to passage $4(\mathrm{P} 4)$ ]. P4 cells were harvested, washed, and formulated for intravenous infusion. MSC identity (CD31, CD34, CD45, CD73, CD90, and CD105) ensured all cell products met test specifications. These cells met the minimal criteria for MSCs based on the definition of the International Society of Cell Therapy. Therefore, we believe that these cells are adipose tissuederived MSCs.

\footnotetext{
${ }^{1}$ Department of Pediatrics, McGovern Medical School, The University of Texas Health Science Center, Houston, Texas.

${ }^{2}$ Celltex Therapeutics Corporation, Houston, Texas.

(C) Mohammed T. Numan, et al., 2017; Published by Mary Ann Liebert, Inc. This Open Access article is distributed under the terms of the Creative Commons Attribution Noncommercial License (http://creativecommons.org/licenses/by-nc/4.0/) which permits any noncommercial use, distribution, and reproduction in any medium, provided the original author(s) and the source are credited.
} 
Table 1. Summary of Biomarkers of Immune System and Autonomic Nervous System by HUTT for Case 1

\begin{tabular}{|c|c|c|}
\hline & $\begin{array}{c}\text { Before MSC } \\
\text { therapy }\end{array}$ & $\begin{array}{c}\text { After } M S C \\
\text { therapy }\end{array}$ \\
\hline Cytokine 13 & $19 \mathrm{pg} / \mathrm{mL}$ & $6 \mathrm{pg} / \mathrm{mL}$ \\
\hline Cytokine 6 & $8 \mathrm{pg} / \mathrm{mL}$ & $<\underset{\text { (normal) }}{<5 \mathrm{pg} / \mathrm{mL}}$ \\
\hline $\begin{array}{l}\text { HR during HUTT } \\
\text { test (upright) }\end{array}$ & $150 / \mathrm{min}$ & $95 / \mathrm{min}$ \\
\hline $\begin{array}{l}\text { Syncope during } \\
\text { HUTT test }\end{array}$ & $\begin{array}{c}\text { Yes at } 4.5 \mathrm{~min} \\
\text { of upright }\end{array}$ & $\begin{array}{l}\text { Completed } \\
30 \text { min upright } \\
\text { with no } \\
\text { syncope }\end{array}$ \\
\hline $\begin{array}{l}\text { Cerebral } \\
\text { perfusion by } \\
\text { NIRS during } \\
\text { HUTT test }\end{array}$ & $\begin{array}{l}\text { Severely } \\
\text { decreased by } \\
>30 \% \text { of her } \\
\text { baseline }\end{array}$ & $\begin{array}{l}\text { No significant } \\
\text { decrease } \\
(<10 \% \\
\text { decrement })\end{array}$ \\
\hline $\begin{array}{l}\text { Sympathetic tone } \\
\text { by Fourier } \\
\text { analysis }\end{array}$ & $\begin{array}{l}\text { Severely } \\
\text { increased } \\
>80 \%\end{array}$ & $\begin{array}{l}\text { Mild increase } \\
\quad(<50 \%)\end{array}$ \\
\hline
\end{tabular}

HR, heart rate; HUTT, head up tilt table; MSC, mesenchymal stem cell; NIRS, near-infrared spectroscopy.

\section{Case 1}

A 22-year-old female followed since 2004 had symptoms of severe dysautonomia, including frequent syncope, severe headaches, and postural tachycardia. She had severe gastrointestinal symptoms of dysphagia, nausea, abdominal pains, and diarrhea (up to 15 times daily). She was wheelchair bound by her OI. Head up tilt table test (HUTT) before MSC infusion showed tachycardia up to $150 \mathrm{bpm}$ with syncope and hypotension after $4 \mathrm{~min}$ of head up tilt. Extensive autoimmune evaluation showed positive antiglutamic acid decarboxylase, antiparietal cell and antifolate receptor antibodies, elevated serum cytokines, and antithyroid peroxidase antibodies. She was initially diagnosed with polyarticular juvenile idiopathic arthritis. She received multiple anti-inflammatory and immunosuppressive agents; however, her symptoms were only partially alleviated and she continued to medically deteriorate. Her maternal aunt had a similar clinical course and died in her early 30s while being treated at the NIH, Bethesda, MD. In September 2014, she received 5 million ASCs/kg by intravenous infusion. At subsequent bimonthly evaluations after ASC therapy, there was dramatic improvement of her multiple symptoms, particularly gastrointestinal complaints, headaches, syncope, and subjectively improved stamina. Her inflammatory biomarkers were repeated 3 months after ASC therapy and showed improvement. After ASC therapy, she completed 30 min of head up position with normal heart rate (HR) and blood pressure (BP) responses and improved sympathetic/ parasympathetic tone depicted by fast Fourier mathematical analysis of HR and BP variability (Table 1).

\section{Case 2}

A 7-year-old male was diagnosed with systemic juvenile idiopathic arthritis with polyarthritis. Magnetic resonance imaging of his knees and hips showed effusions. Multiple therapies included nonsteroidal anti-inflammatory agents and cytotoxic agents. Symptoms increased and he developed abdominal pain and diarrhea. At 5 years of age, he developed hypotension and tachycardia at upright posture with dizziness. Symptoms prevented attendance at school. His family elected ASC treatment and he received 5 million autologous ASCs $/ \mathrm{kg}$ in September 2014. He presented to our center 3 months after his ASC therapy. OI symptoms, arthritic pain, and other symptoms improved such that antiinflammatory and immune modulatory agents were discontinued and he completed $30 \mathrm{~min}$ of HUTT test with normal HR and BP responses and normal cerebral perfusion by near-infrared spectroscopy.

\section{Discussion}

We have demonstrated both by improved symptoms and by laboratory tests the safety and efficacy of autologous ASCs in treating two young patients with autoimmune systemic disease and dysautonomia. Both cases had a severe form of dysautonomia complicated by or secondary to autoimmune processes. Medical therapy initiated in both patients before ASC infusions was intensive, including multiple immune modulatory therapies. We propose that symptoms of dysautonomia improved after modulation of autoimmune components of this syndrome [4]. Human leukoctye antigen-antigen D related (HLA-DR), the major histocompatibility complex II cell surface receptor, interacts with immune cells to cause an immune response. Owing to lack of HLA-DR expression on their surfaces, MSCs have been demonstrated to be immune evasive, and both autologous and allogeneic MSC treatments have achieved promising outcomes in many clinical trials $[5,6]$. Autologous MSC therapy is very safe and without causing potential immune rejections after numerous repeated treatments. Numerous secretomes have been detected in MSCs, which are associated with MSC immunomodulation, trophic activities, angiogenesis, and antiapoptosis. High level expression of anti-inflammatory cytokines from MSCs, such as interleukin-10, interleutin-13, macrophage migration inhibitor factor, and transforming growth factor $\beta$, plays very important roles in inhibition of inflammation and immunomodulation by reacting with most of the immune cells, including: T cells, B cells, natural killer cells, and dendritic cells through various mechanisms, such as cellcell contact and the release of chemokines and cytokines in vivo [7].

\section{Conclusion}

The favorable clinical response in these two young patients warrants further clinical trials using either autologous or allogeneic MSCs for autoimmune diseases could be designed for randomized, double-blind, single-dose versus multiple-dose infusions, while evaluating patient outcomes at a time course up to 24 months and even longer to evaluate the role of MSC therapy on autonomic nervous system and immune dysfunctions, which may be actually interrelated.

\section{Authors Disclosure Statement}

M.T.N., I.J.B., and A.K. have no conflict of interest or disclosures for this study. J.Y. is employed by Celltex Therapeutics Corporation and she contributed for the methods part of this study. 


\section{References}

1. Stewart JM. (2000). Autonomic nervous system dysfunction in adolescents with postural orthostatic tachycardia syndrome and chronic fatigue syndrome is characterized by attenuated vagal Baroreflex and potentiated Sympathetic vasomotion. Pediatr Res 48:218-226.

2. Arnold AC, K Haman, EM Garland, V Raj, WD Dupont, I Biaggioni, D Robertson and SR Raj. (2015). Cognitive dysfunction in postural tachycardia syndrome. Clin Sci (Lond) 128:39-45.

3. Bernardo ME and WE Fibbe. (2013). Mesenchymal stromal cells: sensors and switchers of inflammation. Cell Stem Cell 13:392-402.

4. Krampera M, S Sartoris, F Liotta, A Pasini, R Angeli, L Cosmi, A Andreini, F Mosna, B Bonetti, et al. (2007). Immune regulation by mesenchymal stem cells derived from adult spleen and thymus. Stem Cells Dev 16:797-810.

5. Ankrum JA, JF Ong and JM Karp. (2014). Mesenchymal stem cells: immune evasive, not immune privileged. Nat Biotechnol 32:256-260.

6. Zhao S, R Wehner, M Bornhäuser, R Wassmuth, M Bachmann and M Schmitz. (2010). Immunomodulatory properties of mes- enchymal stromal cells and their therapeutic consequences for immune-mediated disorders. Stem Cells Dev 19:607-614.

7. Blaber SP, RA Webster, CJ Hill, EJ Breen, D Kuah, G Vesey and BR Herbert. (2012). Analysis of in vitro secretion profiles from adipose derived cell populations. J Transl Med 10:172.

$$
\begin{array}{r}
\text { Address correspondence to: } \\
\text { Prof. Mohammed T. Numan } \\
\text { Department of Pediatrics } \\
\text { McGovern Medical School } \\
\text { The University of Texas Health Science Center } \\
6410 \text { Fannin Street, Suite } 425 \\
\text { Houston, TX } 77030
\end{array}
$$

E-mail: mohammed.t.numan@uth.tmc.edu

Received for publication July 4, 2016 Accepted after revision December 12, 2016

Prepublished on Liebert Instant Online December 13, 2016 